\title{
Nucleus Accumbens Activity Dissociates Different Forms of Salience: Evidence from Human Intracranial Recordings
}

\author{
Tino Zaehle, ${ }^{1,2 \star}$ Eva M. Bauch, ${ }^{3 \star}$ Hermann Hinrichs, ${ }^{1}$ Friedhelm C. Schmitt, ${ }^{1}$ Jürgen Voges, ${ }^{1}$ Hans-Jochen Heinze, ${ }^{1,2}$ \\ and Nico Bunzeck ${ }^{3}$ \\ ${ }^{1}$ Departments of Neurology and Stereotactic Neurosurgery, Otto-von-Guericke University, 39120 Magdeburg, Germany, ${ }^{2}$ Department of Behavioral \\ Neurology, Leibniz Institute for Neurobiology, 39120 Magdeburg, Germany, and ${ }^{3}$ Department of Systems Neuroscience, University Medical Center \\ Hamburg-Eppendorf, 20246 Hamburg, Germany
}

Theoretical models and empirical work indicate a critical role of the NAcc in salience processing. For instance, the NAcc not only responds to appetitive and aversive information, but it also signals novelty, contextual deviance, and action monitoring. However, because most studies have investigated only one specific type of salience independently, it remains unclear how the NAcc concurrently differentiates between different forms of salience. To investigate this issue, we used intracranial electroencephalography in human epilepsy patients together with a previously established visual oddball paradigm. Here, three different oddball categories (novel, neutral, and target images) were infrequently presented among a standard scene image, and subjects responded to the target via button press. This task allowed us to differentiate "item novelty" (new vs neutral oddballs) from "contextual deviance" (neutral oddballs vs standard images) and "targetness" (target vs neutral oddballs). Time-frequency analysis revealed a dissociation between item novelty and contextual deviance on the basis of decreases in either $\theta(4-8 \mathrm{~Hz})$ or $\beta$ power $(20-30 \mathrm{~Hz})$. Targetness, on the other hand, was signaled by positive deflections in the stimulus-locked local field potentials, which, importantly, correlated with subjects' reaction times. These findings indicate that, in an ongoing stream of information, the NAcc differentiates between types of salience by distinct neural mechanisms to guide goal-directed behavior.

\section{Introduction}

The NAcc is a core region of the ventral striatum, which has direct and indirect connections to a wide range of brain structures, including the prefrontal cortex, medial temporal lobe, and dopaminergic midbrain (Haber and Knutson, 2009). It has traditionally been associated with reward learning (e.g., O’Doherty, 2004), but recent evidence suggests that it has a much broader function. In particular, the NAcc is involved in goal-directed behavior (Goto and Grace, 2005), and it responds to novelty (Wood and Rebec, 2004), contextual deviance (Axmacher et al., 2010), and aversive stimuli (Becerra et al., 2001; Baliki et al., 2010), which points toward a prominent role in salience processing (Horvitz, 2000; Zink et al., 2003, 2006; Cooper and Knutson, 2008). However, the precise neural mechanisms in support of distinct forms of salience within the NAcc remain unclear.

A distinction between different types of salience can be made on the rationale that stimuli are salient because of (1) their first

\footnotetext{
Received Nov. 13, 2012; revised April 3, 2013; accepted April 10, 2013.

Author contributions: T.Z., E.M.B., H.H., H.-J.H., and N.B. designed research; T.Z., F.C.S., and J.V. performed research; E.M.B. and N.B. analyzed data; T.Z., E.M.B., and N.B. wrote the paper.

This work was supported by grants from the German Research Foundation (Deutsche Forschungsgemeinschaft) to T.Z., J.V., and H.-J.H. (SFB 779), and N.B. (BU 2670/1-1), and Hamburg state cluster of excellence (neurodapt!) to N.B. We thank all patients for their willingness to participate in this study.

The authors declare no competing financial interests.

*T.Z. and E.M.B. contributed equally to this work.

Correspondence should be addressed to Dr. Nico Bunzeck, Department of Systems Neuroscience, University Medical Center Hamburg-Eppendorf, Martinistrasse 52, 20246 Hamburg, Germany. E-mail: n.bunzeck@uke.de.

DOI:10.1523/JNEUROSCI.5276-12.2013

Copyright $\odot 2013$ the authors $\quad 0270-6474 / 13 / 338764-08 \$ 15.00 / 0$
}

encounter (i.e., "item novelty"), (2) their contextual rareness (i.e., "contextual deviance"; here items are familiar to the subject but contextually deviant), or (3) their behavioral significance in a given context (i.e., "targetness"; here rare items require a motor response). Although previous studies could show NAcc activity to contextual deviance, for instance by using intracranial recordings (Axmacher et al., 2010), there is only indirect evidence for the involvement of the NAcc in processing item novelty (e.g., Guitart-Masip et al., 2010; Daniel and Pollmann, 2012). This is surprising given that a prominent theoretical model of novelty processing suggests that the NAcc plays an important role in transferring novelty signals from the medial temporal lobe to the dopaminergic midbrain (Lisman and Grace, 2005; Lisman et al., 2011). This so-called hippocampal-substantia nigra/ventral tegmental area loop is supposed to underlie encoding of novel information into long-term memory possibly via neural $\theta$ oscillations (Duzel et al., 2010).

Here, we used intracranial recordings in seven epilepsy patients together with a modified version of a previously established oddball paradigm (Bunzeck and Duzel, 2006; Bunzeck et al., 2007) that allowed us to differentiate item novelty from contextual deviance and targetness. We predicted that neural responses to contextual deviance emerge in the local field potentials (LFPs) at $\sim 400 \mathrm{~ms}$ (Axmacher et al., 2010), and we assessed whether this response is generic for item novelty and targetness. Furthermore, on the basis of previous scalp recordings investigating novelty and/or saliency (e.g., Brenner et al., 2009; Bunzeck et al., 2011; HajiHosseini et al., 2012), we tested whether neural oscillations in 
A

B

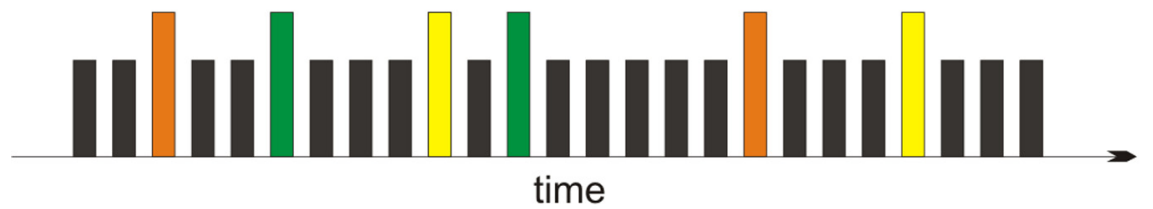

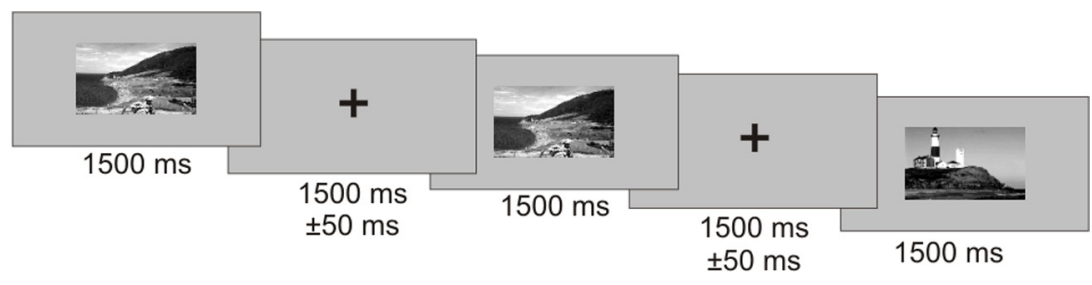

(VLMT) (Helmstaedter et al., 2001), figural memory (DCS) (Weidlich et al., 2001), and sustained attention (d2) (Brickenkamp, 2000). The VLMT measures verbal list learning and memory by assessing recall and recognition of unstructured word lists over immediate and delayed trials. Analogously, the DCS measures learning ability and performance of visual memory by assessing the recall and reproduction of symmetrical geometric drawings. In the "d2" test of attention, subjects are presented with lines of d's and p's, which can have up to two marks on top and below (i.e., a maximum of four marks per letter). The task is to strike out those d's that have exactly two marks on top or two marks below and ignore all other letters; it is timed and has to be performed as fast and accurately as possible.

Treatment planning standards and surgical procedures were performed as described previously (Voges et al., 2002). Briefly, the target for the deep brain stimulation electrode was defined as the point $2 \mathrm{~mm}$ rostral to the anterior border of the anterior commissure at the level

the $\theta(4-8 \mathrm{~Hz})$ and $\beta(20-30 \mathrm{~Hz})$ frequency range are modulated as a function of item novelty and whether they provide a mechanism to differentiate between all three types of salience (i.e., item novelty, contextual deviance, and targetness). Finally, we tested the prediction (again derived from scalp recordings) that enhanced NAcc $\theta$ power during encoding drives subsequent recognition memory (e.g., Klimesch et al., 1996; Osipova et al., 2006).

\section{Materials and Methods}

Task. All subjects were instructed to complete five blocks of a modified visual oddball paradigm (Bunzeck and Duzel, 2006; Bunzeck et al., 2007) using photographs of outdoor scenes. In each block, there were 50 standard images (i.e., one frequently repeated scene), 10 target oddballs (i.e., one infrequently presented scene requiring a button press), 10 neutral oddballs (i.e., one infrequently presented scene), and 10 novel oddballs (i.e., 10 different unfamiliar scene images), yielding a total of 50 stimuli per oddball class (Fig. 1). Before the experiment, the target stimulus was introduced and subjects were required to make a simple button press to each of its subsequent appearance in the experiment using their right index finger. No motor responses were associated with any of the other stimulus classes.

During the experiment, pictures were presented for $1500 \mathrm{~ms}$ followed by a white fixation cross (presented for $1500 \mathrm{~ms}$ ) on gray background (gray-value $=127)$. The intertrial interval was jittered between $-50 \mathrm{~ms}$ and $+50 \mathrm{~ms}$ (uniformly distributed). The order of stimuli was fully randomized. All subjects performed a short practice run before the actual experiment started.

Approximately $15 \mathrm{~min}$ after the oddball paradigm, subjects completed a recognition memory test. Here, all 50 studied novel oddballs (now old items) were presented intermixed with 50 unstudied distractor images (new items), and participants discriminated the old/new status by button presses. Each picture was presented until a button was pressed (old vs new), and this was followed by a fixation cross for $1500 \mathrm{~ms}$. Similar to the oddball task, all subjects performed a short practice run before the actual experiment started.

Participants, surgery, and electrode implantation. Bilateral stereotactically guided implantation of quadripolar brain electrodes (model 3387, Medtronic) in the NAcc (Fig. 2) was performed in seven patients (mean \pm SD age: $40 \pm 9.02$ years; 3 male $/ 4$ female, all right handed) with a history of severe, drug-resistant epilepsy. The study was approved by the local ethics committee (University of Magdeburg), and all patients gave written informed consent.

Table 1 summarizes individual clinical background and neuropsychological test results. Neuropsychological assessment was performed before the surgical intervention and included tests regarding verbal memory of the mid-sagittal plane, 3-4 $\mathrm{mm}$ ventral and 6-8 $\mathrm{mm}$ lateral of the midline. These are standard coordinates, which have to be modified according to the individual planning MRI. An important landmark is the vertical limb of Broca's diagonal band, which can be clearly visualized in coronal MRI scans. The target was placed 2-2.5 mm lateral of this structure. The contacts within the NAcc were placed in the caudomedial part, which, according to histochemical criteria, represents the remnant of the shell area in the primate. Different from rodents, the shell area has regressed in the primate and is no longer clearly distinguishable, except for the fact that it carries the typical receptors.

To further indicate the coordinates of the most caudal NAcc electrode, we transformed all patients' MRI images to MNI space. The resulting MNI coordinates were $(x, y, z)$ as follows: $7,6,-10$ (right hemisphere) and $-8,6$, -10 (left hemisphere). Figure 2 depicts one patient's non-normalized MRI image and the planned trajectories of the leads/electrodes.

Apart from the NAcc, all patients received implantations of electrodes in the bilateral anterior nuclei of thalamus (Samadani and Baltuch, 2007). Data from these electrodes will not be reported in this manuscript. Also, the rationale behind deep brain stimulation in epilepsy patients will be explained in detail elsewhere.

Intraoperatively, the localization of the leads was documented by stereotactic $\mathrm{x}$-ray imaging using $\mathrm{x}$-ray tubes installed in the operating room. Additionally, postoperative CT examination $(2 \mathrm{~mm}$ slice thickness) was performed. After transformation of postoperative CT- and $\mathrm{x}$-ray images with the stereotactic treatment planning MRI, the stereotactic coordinates were defined for each electrode contact of the leads and visualized on frontal sections of the stereotactic brain atlas of Morel. Postoperatively, electrode leads were externalized allowing electrical test stimulation with different parameters and the recording from the depth contacts in different psychological tasks. Subsequently, electrode cables were connected to an impulse generator located beneath the left pectoral muscle (Kinetra, Medtronic) similar to a cardiac pacemaker.

Data recording and analysis. All recordings were conducted using a Walter Graphtek system (Walter Graphtek). Intracranial EEG (iEEG) signals were digitized continuously at a sampling rate of $512 \mathrm{~Hz}$, and behavioral responses were made via an EEG-compatible response pad. Because of technical issues, behavioral responses could not be recorded during the oddball paradigm for one subject. As described above, there were four intracranial electrode contacts (platinumiridium contacts, $1.5 \mathrm{~mm}$ wide with $1.5 \mathrm{~mm}$ edge-to-edge distance) both in the left and right NAcc. Following previous studies (Staudigl et al., 2012; e.g., Litvak et al., 2012), each electrode contact was referenced to its neighboring electrode (three bipolar channels per hemisphere: 1-2, 2-3, 3-4) to limit the effects of volume conduction from 


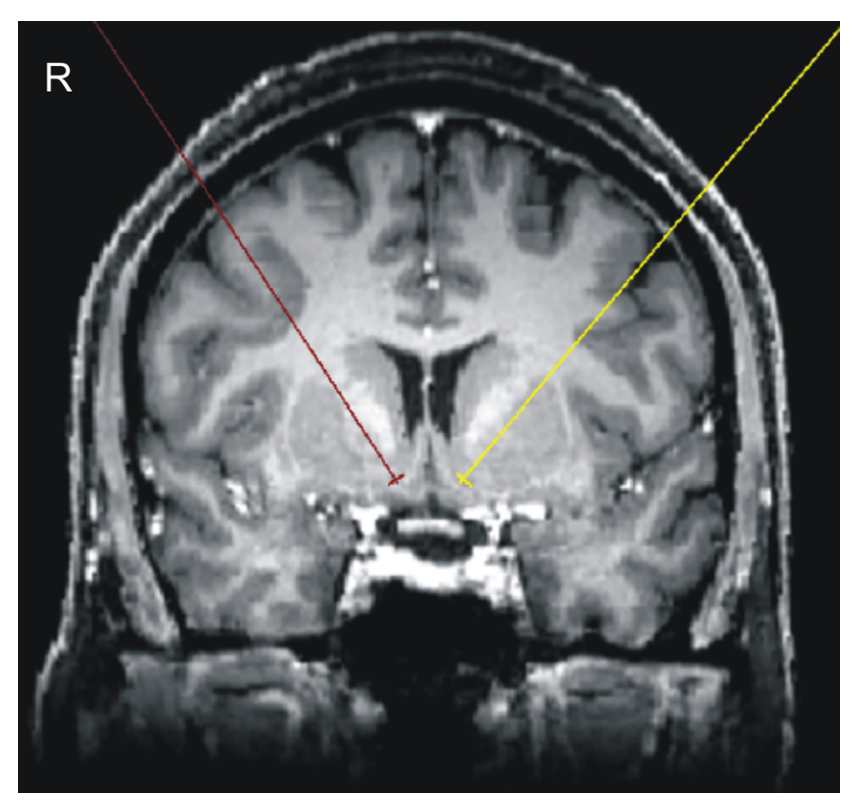

Figure 2. Individual T1-weighted MRI image. For each patient, an individual MRI image was acquired before bilateral NAcc implantation. Red and yellow lines represent the planned trajectories of the leads/electrodes.

distant sources and to maximize spatial selectivity. Data were analyzed with MATLAB version 7.8 (MathWorks) and EEGlab toolbox (Delorme and Makeig, 2004).

Analysis of local field potentials. The continuous iEEG data were offline filtered between 0.5 and $20 \mathrm{~Hz}$ and epoched from $100 \mathrm{~ms}$ before to $1000 \mathrm{~ms}$ after item onset. To remove possible artifacts, trials were automatically rejected when they contained iEEG activity that exceeded 3 SDs from the mean at a specific bipolar channel. Subsequently, all trials were visually inspected and manually rejected if they still contained any artifacts. None of the analyzed trials contained epileptic spike activity. This step resulted in the following number of trials per condition: standard, 233 (range 196-250); target, 47 (43-50); neutral, 47 (41-50); and novel, 46 (39-50). Subsequently, LFP waveforms were computed for each subject and bipolar channel separately by averaging all trials per condition.

To statistically test whether LFPs were modulated by item novelty (novel vs neutral), contextual deviance (neutral vs standard), or targetness (targets vs neutral) repeated-measures ANOVAs were conducted on the mean amplitude for the time window 100-500 ms (see below). These analyses included the within-subject factors hemisphere (left/right), site ( 3 bipolar channels), and item type: deviance (standard/neutral), novelty (novel/neutral), or targetness (target/neutral), respectively. Significant main effects and interactions were followed by additional analyses to understand the nature of the effect. Greenhouse-Geisser-corrected degrees of freedom ( $\mathrm{df}$ ) and $p$ values are reported where necessary to account for possible violations of the sphericity assumption (Keselman and Rogan, 1980).

Time-frequency analysis. iEEG data were high-pass filtered with a cutoff point of $0.5 \mathrm{~Hz}$ to remove slow drifts, and segmented into epochs that extended from $-800 \mathrm{~ms}$ to $2100 \mathrm{~ms}$. This epoch length ensured that time-frequency information could be extracted from $-200 \mathrm{~ms}$ before until $1000 \mathrm{~ms}$ after stimulus onset without any edge effects. Artifact detection included an automatic and manual step (as described above). None of the analyzed trials contained epileptic spike activity.

Spectral decomposition was applied to the preprocessed data at a trialby-trial level using Morlet wavelets (Percival and Walden, 1993) in $1 \mathrm{~Hz}$ steps in the frequency range of 4 to $30 \mathrm{~Hz}$ (Niedermeyer and da Silva, 2004). The analysis was conducted with 4 cycles in the lower frequency range and 6 cycles for the higher frequencies with a sliding time window of $20 \mathrm{~ms}$ between $-200 \mathrm{~ms}$ and $1 \mathrm{~s}$. The frequency power was baseline corrected to the average frequency power in the time window from -200 $\mathrm{ms}$ to $-100 \mathrm{~ms}$ before item onset via a subtraction approach for each frequency $(4-30 \mathrm{~Hz})$ across each data point of the epoch (see e.g., Hanslmayr et al., 2009). Finally, the time-frequency power across all trials was averaged for each condition (i.e., standard, target, novel, and neutral events). The mean number of trials (range) for those four conditions were $231(196-250), 47(44-50), 47(39-50)$, and 47 (39-50), respectively.

As for the LFPs, statistical analysis for $\theta$ power $(4-8 \mathrm{~Hz})$ and $\beta$ power $(20-30 \mathrm{~Hz})$ was based on ANOVAs with the within-subject factors hemisphere (left/right), electrode site (3 bipolar channels), and item type (item novelty: novel/neutral, contextual deviance: neutral/standard, and targetness: target/neutral).

The nature of our paradigm and concept of what defines novelty, contextual salience, and targetness require a direct comparison between novel versus neutral (item novelty), neutral versus standards (contextual deviance), and targets versus neutral (targetness). All other direct comparisons (e.g., targets vs novel) would be difficult to interpret because these conditions differ in more than one dimension (e.g., targets are familiar and require a motor response vs novel items that do not require a motor response). Therefore, entering all conditions into one statistical model (e.g., one ANOVA) would be unjustified.

All reported $p$ values are based on two-tailed tests.

\section{Results}

Behavior: oddball task

All subjects performed the task according to the instructions. They responded with high accuracy to the target stimulus (hitrate, $0.97 \pm 0.03$; false-alarm rate, $0.01 \pm 0.01$; average reaction time, $588.83 \pm 106.43$; mean \pm SEM).

\section{Behavior: recognition memory}

One patient had to be excluded from the analyses because he did not perform the task according to the instruction (i.e., he constantly pressed only one button to all images). For the remaining six subjects, the hit-rate was $0.45 \pm 0.31$, false-alarm rate was $0.29 \pm 0.26$, and resulting D-prime (Stanislaw and Todorov, 1999) was $0.58 \pm$ 0.32 . Although this relatively low D-prime indicates poor recognition memory performance, it was positive for each patient and above chance level across the entire group $(p<0.05)$.

\section{LFPs}

The grand averaged LFP signals from the nucleus accumbens for standard, neutral, novel, and target events are displayed in Figure 3.

Repeated-measures ANOVAs on the mean amplitudes were conducted for the time window 100-500 ms and the conditions "novel versus neutral" (item novelty), "neutral versus standard" (contextual deviance), and "target versus neutral" (targetness) (see Materials and Methods). This particular time window was chosen because contextual deviance effects in the NAcc were reported to peak at $\sim 400 \mathrm{~ms}$ (Axmacher et al., 2010) and because neural novelty responses can emerge at the scalp surface already at $\sim 100 \mathrm{~ms}$ (Tsivilis et al., 2001; Bunzeck et al., 2009).

The ANOVA on targetness revealed a significant main effect $\left(F_{(1,6)}=10.33 ; p<0.05\right)$, which was most pronounced at L2 $(p<$ 0.05 ; see Fig. 3$)$. There were no significant main effects or interactions for contextual deviance $(p>0.123)$ or item novelty $(p>0.113)$.

The direct comparison between the LFPs for targetness (targets-neutral) versus novelty (novel-neutral), and targetness (targets-neutral) versus contextual deviance (neutral-standards), respectively, revealed a significant $(p<0.05)$ and a marginal significant difference $(p=0.089)$ at channel L2.

To further link the LFP effects with behavior, a correlation analysis was performed between subjects' reaction times and signal changes to target items (100-500 ms). Here, we first rectified individual LFPs by computing their absolute value (Sauleau et al., 
Table 1. Patient data

\begin{tabular}{|c|c|c|c|c|c|c|c|c|c|c|c|c|}
\hline \multirow[b]{2}{*}{ Patient no. } & \multirow[b]{2}{*}{$\begin{array}{l}\text { Sex, age, duration of } \\
\text { epilepsy (years) }\end{array}$} & \multicolumn{5}{|l|}{ Epilepsy } & \multirow[b]{2}{*}{$\begin{array}{l}\text { IQ } \\
\text { (HAWIE-R) }\end{array}$} & \multicolumn{3}{|l|}{ Verbal memory } & \multirow{2}{*}{$\begin{array}{l}\text { Figural } \\
\text { memory } \\
\text { (z-score) }\end{array}$} & \multirow{2}{*}{$\begin{array}{l}\text { Sustained } \\
\text { attention } \\
\text { (z-score) }\end{array}$} \\
\hline & & Syndrome & Lateralization & Seizure onset & Etiology & AEDs & & $\begin{array}{l}\text { Immediate free } \\
\text { recall (z-score) }\end{array}$ & $\begin{array}{l}\text { Delayed free } \\
\text { recall (z-score) }\end{array}$ & $\begin{array}{l}\text { Recognition } \\
\text { (z-score) }\end{array}$ & & \\
\hline A01 & $F, 36,15$ & Multifocal & Bilateral & Frontotemporal & Cryptogenic & $\begin{array}{l}\text { ZNS } 400 \mathrm{mg} \\
\text { LCM } 400 \mathrm{mg} \\
\text { OXC } 1200 \mathrm{mg}\end{array}$ & 68 & $38(-1.6)$ & $8(-1.3)$ & $11(-0.75)$ & $25(-1.4)$ & $350(-0.5)$ \\
\hline $\mathrm{A} 02$ & $F, 52,19$ & Multifocal & Bilateral & Mesiotemporal & Cryptogenic & $\begin{array}{l}\text { LCM } 400 \text { mg } \\
\text { LTG } 200 \mathrm{mg}\end{array}$ & 74.2 & $40(-0.65)$ & $5(-1.6)$ & $9(-1)$ & $8(-1.6)$ & $199(-2.2)$ \\
\hline $\mathrm{A} 03$ & $M, 35,9$ & Focal & Right & Temporal & $\begin{array}{l}\text { Right temporal } \\
\text { encephalocele }\end{array}$ & $\begin{array}{l}\text { LEV } 2000 \mathrm{mg} \\
\text { ESL } 1200 \mathrm{mg}\end{array}$ & 124.9 & $57(-0.65)$ & $12(0.2)$ & $15(1.1)$ & $39(-1)$ & $486(0)$ \\
\hline A04 & $F, 28,12$ & Multifocal & Bilateral & Temporal & Cryptogenic & $\begin{array}{l}\text { LTG } 200 \mathrm{mg} \\
\text { LCM } 200 \mathrm{mg}\end{array}$ & 94 & $53(-0.4)$ & $13(0.2)$ & $15(1.1)$ & $23(-1)$ & $424(-0.8)$ \\
\hline A05 & $M, 40,31$ & Focal & Left & Temporal & $\begin{array}{l}\text { Left hippocampal } \\
\text { sclerosis }^{a}\end{array}$ & $\begin{array}{l}\text { LTG } 400 \mathrm{mg} \\
\text { LCM } 400 \mathrm{mg}\end{array}$ & 90.2 & $36(-1.6)$ & $9(-0.9)$ & $9(-1.3)$ & $16(-1.6)$ & $275(-2.2)$ \\
\hline A06 & $M, 41,12$ & Multifocal & Bilateral & Frontotemporal & Cryptogenic & & 103 & $51(-0.1)$ & $9(-0.9)$ & $12(-0.5)$ & $37(0.8)$ & $507(0.7)$ \\
\hline A07 & $F, 52,17$ & Focal & Left & Temporal & Cryptogenic & $\begin{array}{l}\text { LTG } 250 \mathrm{mg} \\
\text { LCM } 400 \mathrm{mg}\end{array}$ & 78.6 & $62(1.6)$ & $12(0.2)$ & $11(-0.7)$ & $40(0.9)$ & $318(-1.5)$ \\
\hline
\end{tabular}

AEDs, Antiepileptic drugs; F, female; M, male; HAWIE-R, Hamburg-Wechsler Intelligence Test for Adults; ZNS, zonisamide; LCM, lacosamide; OXC, oxcarbazepine; LTG, lamotrigine; LEV, levetiracetam; ESL, eslicarbazepine acetate. ${ }^{a}$ The patient underwent a left cortico-amygdalohippocampectomy 9 years before deep brain stimulation intervention.
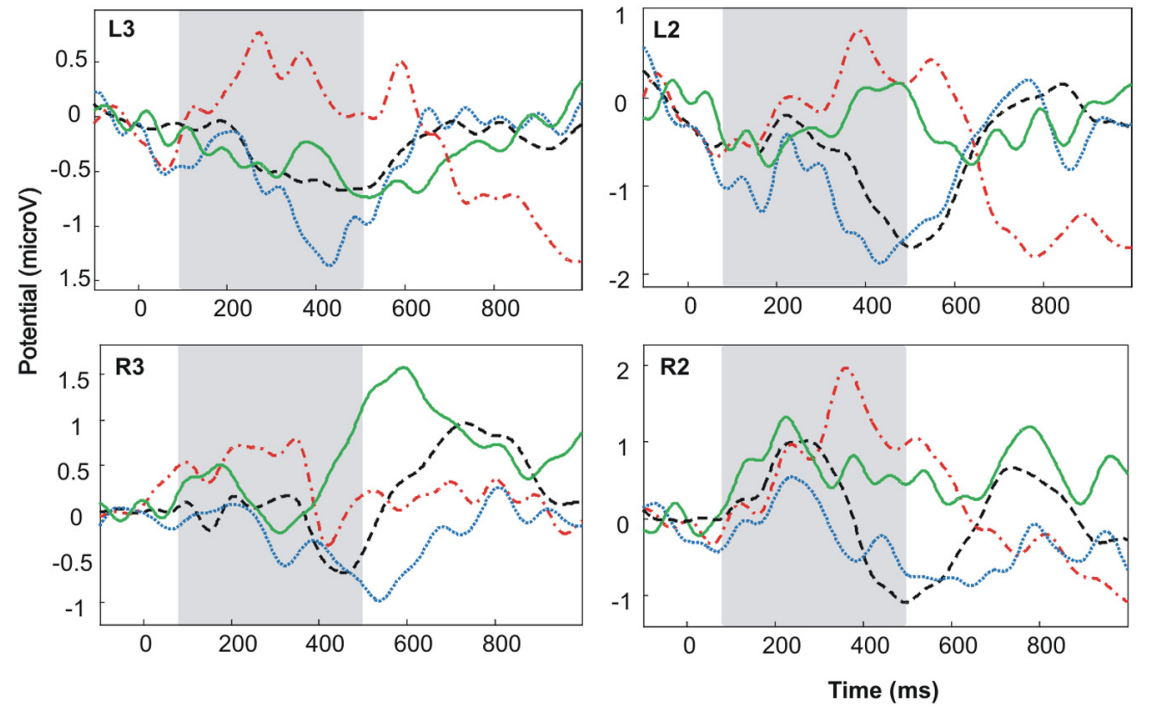

Time (ms)
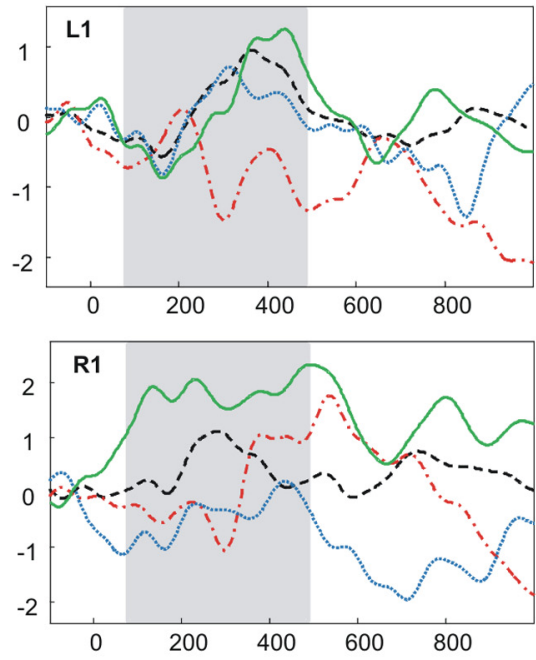

novel …... neutral ---. standard - - target

Figure 3. Grand mean LFPs for all conditions and bipolar channels. There was a significant main effect of targetness in the time window of interest (100 - 500 ms, highlighted in gray), which was most pronounced at $\mathrm{L} 2$ and expressed as positive deflection for target oddballs versus neutral oddballs. Positive values are plotted upward; waveforms are low-pass filtered (15 Hz) for display purposes.

2009) and used the nonparametric measure Spearman's $\rho(\rho)$, which seems particularly useful for small sample sizes, and it offers the advantage of being less sensitive to possible outliers. This analysis revealed a statistically significant correlation for R2 $(\rho=0.87, p=0.019)$ but no other contact $(p>0.05)$ (Fig. 4A).

\section{Time-frequency analysis}

Data were analyzed with respect to their oscillatory power in the $\theta(4-8 \mathrm{~Hz})$ and $\beta$ range $(20-30 \mathrm{~Hz})$. Consistent with the LFP data, the time window of interest for statistical analyses was $100-$ $500 \mathrm{~ms}$.

ANOVA on mean oscillatory $\theta$ power $(4-8 \mathrm{~Hz})$ revealed no significant item novelty effect (neutral-novel, $p=0.244$ ). However, planned paired sample $t$ tests (see Introduction; Bunzeck et al., 2011) showed a significant $\theta$ power decrease for novel compared with neutral items for the right bipolar channel R2 $(p<$ 0.05; Fig. $5 C$ ). The ANOVAs for contextual deviance (neutral vs standard) and targetness (targets vs neutral) revealed no significant effects $(p>0.335)$.

The direct comparison of $\theta$ power at R2 for item novelty (novel-neutral) versus contextual deviance (neutral-standards) and contextual deviance (neutral-standards) versus targetness (target-neutral), respectively, resulted in a significant $(p<0.05)$ and marginal significant difference $(p=0.060)$.

In a next step, ANOVAs were conducted for the $\beta$ frequency range $(20-30 \mathrm{~Hz} ; 100-500 \mathrm{~ms})$. For contextual deviance (standard vs neutral), there was a significant interaction between contextual deviance and hemisphere $\left(F_{(1,6)}=10.07 ; p<0.05\right)$. Further analyses, separate for the left and right hemisphere (averaged across all bipolar channels of the corresponding site), showed significant effects for left $\left(F_{(1,6)}=12.71 ; p<0.05\right)$ but not right NAcc $(p=0.544)$. Further post hoc $t$ tests revealed that this effect was mainly driven by $\beta$ power decreases for neutral items in contrast to standard items at L2 ( $p<0.05$; see Fig. $5 A)$. The ANOVAs for item novelty (novel vs neutral items) and tar- 

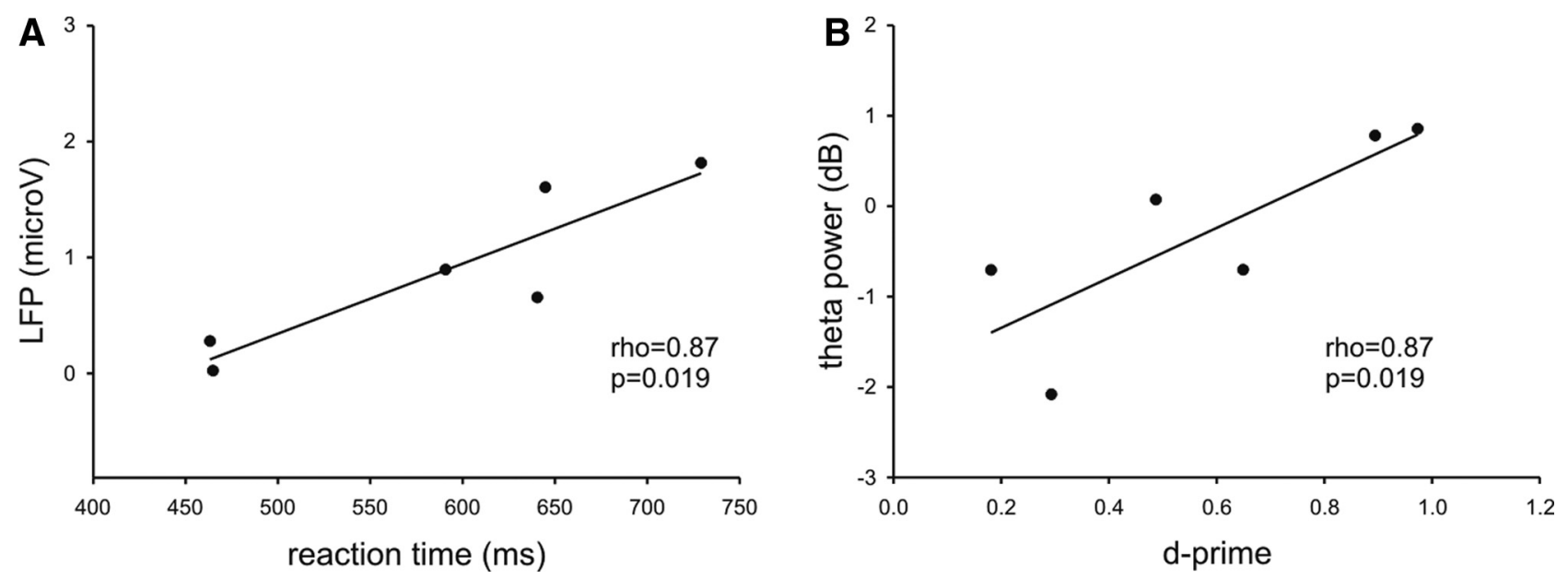

Figure 4. Relationship between signal changes and behavior. $A, A t R 2$, there was a significant correlation between LFPs ( $100-500 \mathrm{~ms}, y$-axis) and reaction time to targets ( $x$-axis). LFPs represent absolute values. $\boldsymbol{B}$, At R2, there was a positive correlation between changes in $\theta$ power in response to novel items ( $y$-axis) and subsequent recognition performance (D-prime, $x$-axis).
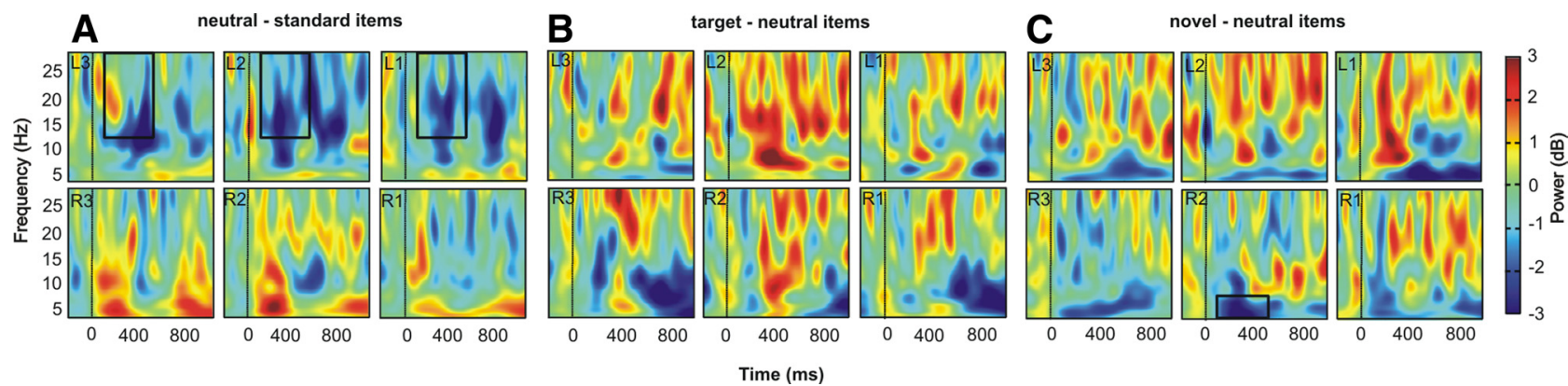

Figure 5. Time-frequency plots. A, At left bipolar channels, $\beta$ power decreased for contextual deviance (neutral oddballs vs standards). C, At R2, $\theta$ power decreased for item novelty (novel vs neutral oddballs). $\boldsymbol{B}$, There were no statistically significant targetness effects in the time window of interest (100-500 ms) in the $\theta$ and $\beta$ band. The time-frequency plots were smoothed for visual purposes.

getness (target vs neutral items) did not reveal any significant effects $(p>0.151)$.

The direct comparisons of $\beta$ power at L2 for contextual deviance (neutral-standards) versus item novelty (novel-neutral) and contextual deviance (neutral-standards) versus targetness (targets-neutral), respectively, revealed a significant $(p<0.05)$ and marginal significant difference $(p=0.078)$.

\section{Relationship between NAcc $\theta$ and recognition memory}

We further investigated the relationship between the noveltyrelated $\theta$ effect at bipolar channel R2 and subsequent recognition memory performance. We found a positive correlation between the mean $\theta$ power to novel oddballs (time window $100-500 \mathrm{~ms}$ ) and D-prime $(\rho=0.87 ; p=0.019$; Fig. $4 B)$.

We computed the correlation between D-prime and $\theta$ power instead of the DM effect (difference resulting from later memory) because most participants had an insufficient number of trials for remember and/or forgotten items (Paller et al., 1987).

\section{Discussion}

We used intracranial recordings to investigate the neural mechanisms of salience processing in the NAcc. Our results demonstrate that oscillatory $\theta$ power decreases closely relate to item novelty, whereas contextual deviance is signaled by changes in $\beta$ oscillations. Moreover, LFPs signaled targetness and predicted subjects' reaction times. These findings suggest that the NAcc concurrently differentiates between different types of salience by distinct neural mechanisms to guide goal-directed behavior.
Theoretical models suggest that the NAcc is an important relay station for the transfer of neural novelty signals from the medial temporal lobe (including hippocampus and surrounding cortex) to dopaminergic midbrain regions (Lisman and Grace, 2005; Lisman et al., 2011). Evidence comes primarily from animal studies showing, for instance, that stimulation of the ventral subiculm (a primary output structure of the hippocampus) leads to increased firing of the NAcc, which, by inhibiting the ventral pallidum, increases the number of tonically activated dopamine neurons in the substantia nigra/ ventral tegmental area (Floresco et al., 2001, 2003). Furthermore, in rats the exploration of novel, but not familiar, environments increases neural firing in the NAcc (Wood and Rebec, 2004). Our findings conform to this work, and they suggest that $\theta$ seem to be the primary frequency band by which stimulus novelty is signaled in the human NAcc.

In physiological terms, $\theta$ oscillations may allow for binding the distributed neural assemblies that jointly signal novelty/ familiarity processing (Buzsaki and Draguhn, 2004). In rats hippocampal $\theta$ has been related to the exploration of novelty by showing a reduction of $\theta$ frequency in novel compared with familiar environments (Jeewajee et al., 2008). In humans, $\theta$ power over frontal and temporal MEG sensors was attenuated for novel items, and it increased with stimulus repetition (Bunzeck et al., 2011). Our results extend these findings to the NAcc by showing decreased $\theta$ power to novel in contrast to neutral oddballs (i.e., repeated scene images). 
Along the same lines, within the network of novelty sensitive brain regions, $\theta$ oscillations have been suggested to provide a mechanism for mnemonic functions (Cashdollar et al., 2009; Nyhus and Curran, 2010; Fell and Axmacher, 2011). This notion is based on animal studies showing consistent $\theta$ activity patterns during spatial memory tasks in the hippocampus, prefrontal cortex, and ventral striatum (for review, see Duzel et al., 2010). In humans, M/EEG studies (e.g., Klimesch et al., 1996; Mölle et al., 2002; Osipova et al., 2006; Hanslmayr et al., 2011) demonstrated that $\theta$ power during encoding is enhanced for items that are later remembered versus items that are later forgotten (so-called "DM effect") (Paller et al., 1987). Although our positive correlation between $\mathrm{D}$-prime (i.e., recognition memory accuracy) and $\theta$ power for novel items (Fig. $4 B$ ) is consistent with these scalp recordings, and therefore provides further evidence for a specific role of the NAcc not only in novelty processing but also in declarative memory encoding, there are other studies revealing the opposite pattern (i.e., decreased $\theta$ for later remembered items) (e.g., Sederberg et al., 2007; Guderian et al., 2009; Burke et al., 2013). It has been argued before that differences in stimulus material, testing procedures (Duzel et al., 2010), or postprocessing steps (Burke et al., 2013) might help to explain these diverging findings. Clearly, future work is needed to explore how $\theta$ novelty effects relate to subsequent memory performance.

In our paradigm, contextual deviance, which was induced by the rare occurrence of repeated items, was associated with decreased $\beta$ power. This finding partly conforms to previous human M/EEG studies suggesting that neural oscillations in the $\beta$ frequency range signal deviance. For instance, scalp recorded $\beta$ power increases in response to rare auditory sounds (in contrast to frequent sounds) in healthy controls, and this effect was diminished in schizophrenia patients (Brenner et al., 2009). Similarly, increases in $\beta$ power (again as measured by scalp M/EEG) were linked with salience in sensory gating paradigms (Kisley and Cornwell, 2006), processing of unexpected rewards (HajiHosseini et al., 2012), and reward anticipation (Bunzeck et al., 2011). Although these scalp recordings and our intracranial data point toward a role of $\beta$ in deviance processing, it should be noted that the effects in our iEEG study and the outlined scalp recordings have opposing directions (increases vs decreases in $\beta$ ). Because scalp recorded $\mathrm{M} / \mathrm{EEG}$ signals are unlikely to reflect direct NAcc activity, it remains unclear whether and how both effects (NAcc and scalp surface) are related.

As evident in the LFPs, the NAcc also signaled targetness (target vs neutral oddballs) and activity changes correlated with reaction times. Because target stimuli were not only contextually deviant (as neutral oddballs) but also required a motor response, this condition was behaviorally most relevant and could be described as "task-driven salient" (Kisley and Cornwell, 2006). Indeed, the NAcc has been proposed to play a prominent role in goal-directed behavior by integrating inputs from other limbic structures and the prefrontal cortex (Goto and Grace, 2005). More precisely, Goto and Grace (2005) pointed out that the NAcc is, in anatomical terms, ideally located to integrate affective information from the amygdala, contextual information from the medial temporal lobe, and executive/motor plans from prefrontal regions to guide goal-directed behavior. Our findings support this notion, and they are in line with previous intracranial recordings in humans, showing that the NAcc is involved in action monitoring (Münte et al., 2007, 2008) possibly by integrating signals from dopaminergic midbrain regions (Boehler et al., 2011). It should be noted that changes in LFPs do not allow direct conclusions regarding increases or decreases in underlying neural activity. Therefore, the observed positive correlation (Fig. 4A) can be taken as evidence for a relationship between changes in neural activity and reaction times rather than evidence for increased neural activity as a function of reaction times.

In contrast to our expectation, we did not find significant contextual deviance effects in the LFPs. This is inconsistent with a previous iEEG study (Axmacher et al., 2010) and might be the result of at least two factors. First, the study designs differ in several ways: most importantly, Axmacher et al. (2010) induced contextual deviance by changes in stimulus category (faces vs houses) and background color (red vs green); in contrast, we only used one stimulus category (scenes) and contextual deviance was induced by the infrequent occurrence of one (repeated) oddball. Furthermore, in our study, subjects used button presses only to report the presentation of a target image; in Axmacher et al. (2010), subjects had to rate the pleasantness of each item (also by button presses). Apart from the study design, the second main difference lies in the clinical population: while we investigated patients suffering from drug-resistant epilepsy, Axmacher et al. (2010) recruited patients with major depression. Although both conditions are not primarily associated with the NAcc, there is some evidence indicating differential pathological changes of the NAcc in depression (Warner-Schmidt et al., 2012) and epilepsy (Deransart et al., 2001).

Several other human recording studies of the NAcc have focused on the neural mechanisms of reward processing (e.g., Cohen et al., 2009, 2012). One of the interesting findings with regard to our results is that anticipation of monetary wins, in contrast to losses, enhances $\theta$ power (Cohen et al., 2012). Together with our observation of changes in $\theta$ to novel items, this suggests that NAcc $\theta$ oscillations may underlie both reward and novelty processing. Indeed, $\theta$ power at the scalp surface (using MEG) changes in response to novelty and reward (Bunzeck et al., 2011), and there are a number of studies pointing toward a functional and anatomical overlap of reward and novelty processing (Guitart-Masip et al., 2010; e.g., Bunzeck et al., 2010). It remains unclear, however, why novelty and reward processing lead to opposite changes in NAcc $\theta$ power while they both increase hemodynamic activity in other parts of the mesolimbic system, such as the substantia nigra/ventral tegmental area (Wittmann et al., 2005; Adcock et al., 2006; Bunzeck and Duzel, 2006; Bunzeck et al., 2007)

On a final note, we would like to acknowledge that a larger sample size could increase the power of our statistical results. However, because access to suitable patients is limited and requires a careful selection based on clinical grounds, our sample size is (as in comparable studies, e.g., Cohen et al., 2009, 2012; Axmacher et al., 2010) smaller than 10. To keep the number of statistical comparisons to a minimum, we limited our analyses to one predefined time window of interest, the LFPs, and two frequency bands for which we had a priori defined hypotheses. Therefore, at this stage, we refrain from further exploratory analyses of other time points and frequency bands.

Together, our findings demonstrate that, within an ongoing stream of information, the NAcc codes different forms of salience by distinct neural mechanisms: decreases in $\theta$ power signaled item novelty, decreases in $\beta$ power signaled contextual deviance, and positive deflections in the stimulus-locked LFP signaled targetness. These findings further indicate the importance of the NAcc in integrating information from interconnected brain regions, and they suggest that the NAcc differentiates concurrently behaviorally relevant from irrelevant forms of salience to guide decision-making. Furthermore, the positive relationship be- 
tween $\theta$ power during encoding and subsequent recognition memory provides evidence for a role of NAcc $\theta$ oscillation in mnemonic functions possibly by binding neural activity that is shared between different mesolimbic brain regions (i.e., medial temporal lobe and dopaminergic midbrain).

\section{References}

Adcock RA, Thangavel A, Whitfield-Gabrieli S, Knutson B, Gabrieli JD (2006) Reward-motivated learning: mesolimbic activation precedes memory formation. Neuron 50:507-517. CrossRef Medline

Axmacher N, Cohen MX, Fell J, Haupt S, Dümpelmann M, Elger CE, Schlaepfer TE, Lenartz D, Sturm V, Ranganath C (2010) Intracranial EEG correlates of expectancy and memory formation in the human hippocampus and nucleus accumbens. Neuron 65:541-549. CrossRef Medline

Baliki MN, Geha PY, Fields HL, Apkarian AV (2010) Predicting value of pain and analgesia: nucleus accumbens response to noxious stimuli changes in the presence of chronic pain. Neuron 66:149-160. CrossRef Medline

Becerra L, Breiter HC, Wise R, Gonzalez RG, Borsook D (2001) Reward circuitry activation by noxious thermal stimuli. Neuron 32:927-946. CrossRef Medline

Boehler CN, Bunzeck N, Krebs RM, Noesselt T, Schoenfeld MA, Heinze HJ, Münte TF, Woldorff MG, Hopf JM (2011) Substantia nigra activity level predicts trial-to-trial adjustments in cognitive control. J Cogn Neurosci 23:362-373. CrossRef Medline

Brenner CA, Kieffaber PD, Clementz BA, Johannesen JK, Shekhar A, O’Donnell BF, Hetrick WP (2009) Event-related potential abnormalities in schizophrenia: a failure to "gate in" salient information? Schizophr Res 113:332-338. CrossRef

Brickenkamp R (2000) Test d2: Aufmerksamkeits-Belastungs-Test, Ed 9. Göttingen: Hogrefe.

Bunzeck N, Düzel E (2006) Absolute coding of stimulus novelty in the human substantia nigra/VTA. Neuron 51:369-379. CrossRef Medline

Bunzeck N, Schütze H, Stallforth S, Kaufmann J, Düzel S, Heinze HJ, Düzel E (2007) Mesolimbic novelty processing in older adults. Cereb Cortex 17: 2940-2948. CrossRef Medline

Bunzeck N, Doeller CF, Fuentemilla L, Dolan RJ, Duzel E (2009) Reward motivation accelerates the onset of neural novelty signals in humans to 85 milliseconds. Curr Biol 19:1294-1300. CrossRef Medline

Bunzeck N, Dayan P, Dolan RJ, Duzel E (2010) A common mechanism for adaptive scaling of reward and novelty. Hum Brain Mapp 31:1380-1394. CrossRef Medline

Bunzeck N, Guitart-Masip M, Dolan RJ, Düzel E (2011) Contextual novelty modulates the neural dynamics of reward anticipation. J Neurosci 31: 12816-12822. CrossRef Medline

Burke JF, Zaghloul KA, Jacobs J, Williams RB, Sperling MR, Sharan AD, Kahana MJ (2013) Synchronous and asynchronous $\theta$ and $\gamma$ activity during episodic memory formation. J Neurosci 33:292-304. CrossRef Medline

Buzsáki G, Draguhn A (2004) Neuronal oscillations in cortical networks. Science 304:1926-1929. CrossRef Medline

Cashdollar N, Malecki U, Rugg-Gunn FJ, Duncan JS, Lavie N, Duzel E (2009) Hippocampus-dependent and -independent theta-networks of active maintenance. Proc Natl Acad Sci U S A 106:20493-20498. CrossRef Medline

Cohen MX, Axmacher N, Lenartz D, Elger CE, Sturm V, Schlaepfer TE (2009) Good vibrations: cross-frequency coupling in the human nucleus accumbens during reward processing. J Cogn Neurosci 21:875-889. CrossRef Medline

Cohen MX, Bour L, Mantione M, Figee M, Vink M, Tijssen MA, van Rootselaar AF, van den Munckhof P, Schuurman PR, Denys D (2012) Topdown-directed synchrony from medial frontal cortex to nucleus accumbens during reward anticipation. Hum Brain Mapp 33:246-252. CrossRef Medline

Cooper JC, Knutson B (2008) Valence and salience contribute to nucleus accumbens activation. Neuroimage 39:538-547. CrossRef Medline

Daniel R, Pollmann S (2012) Striatal activations signal prediction errors on confidence in the absence of external feedback. Neuroimage 59:34573467. CrossRef Medline

Delorme A, Makeig S (2004) EEGLAB: an open source toolbox for analysis of single-trial EEG dynamics including independent component analysis. J Neurosci Methods 134:9-21. CrossRef Medline
Deransart C, Landwehrmeyer GB, Feuerstein TJ, Lücking CH (2001) Upregulation of $\mathrm{D} 3$ dopaminergic receptor mRNA in the core of the nucleus accumbens accompanies the development of seizures in a genetic model of absence-epilepsy in the rat. Mol Brain Res 94:166-177. CrossRef Medline

Düzel E, Penny WD, Burgess N (2010) Brain oscillations and memory. Curr Opin Neurobiol 20:143-149. CrossRef Medline

Fell J, Axmacher N (2011) The role of phase synchronization in memory processes. Nat Rev Neurosci 12:105-118. CrossRef Medline

Floresco SB, Todd CL, Grace AA (2001) Glutamatergic afferents from the hippocampus to the nucleus accumbens regulate activity of ventral tegmental area dopamine neurons. J Neurosci 21:4915-4922. Medline

Floresco SB, West AR, Ash B, Moore H, Grace AA (2003) Afferent modulation of dopamine neuron firing differentially regulates tonic and phasic dopamine transmission. Nat Neurosci 6:968-973. CrossRef Medline

Goto Y, Grace AA (2005) Dopaminergic modulation of limbic and cortical drive of nucleus accumbens in goal-directed behavior. Nat Neurosci 8:805-812. CrossRef Medline

Guderian S, Schott BH, Richardson-Klavehn A, Düzel E (2009) Medial temporal $\theta$ state before an event predicts episodic encoding success in humans. Proc Natl Acad Sci U S A 106:5365-5370. CrossRef Medline

Guitart-Masip M, Bunzeck N, Stephan KE, Dolan RJ, Düzel E (2010) Contextual novelty changes reward representations in the striatum. J Neurosci 30:1721-1726. CrossRef Medline

Haber SN, Knutson B (2010) The reward circuit: linking primate anatomy and human imaging. Neuropsychopharmacology 35:4-26. CrossRef Medline

HajiHosseini A, Rodríguez-Fornells A, Marco-Pallarés J (2012) The role of $\beta-\gamma$ oscillations in unexpected rewards processing. Neuroimage 60:1678 1685. CrossRef Medline

Hanslmayr S, Leipold P, Pastötter B, Bäuml KH (2009) Anticipatory signatures of voluntary memory suppression. J Neurosci 29:2742-2747. CrossRef Medline

Hanslmayr S, Volberg G, Wimber M, Raabe M, Greenlee MW, Bäuml KH (2011) The relationship between brain oscillations and BOLD signal during memory formation: a combined EEG-fMRI study. J Neurosci 31: 15674-15680. CrossRef Medline

Helmstaedter C, Lendt M, Lux S (2001) Verbaler Lern- und MerkfähigkeitstestManual. Göttingen: Hogrefe.

Horvitz JC (2000) Mesolimbocortical and nigrostriatal dopamine responses to salient non-reward events. Neuroscience 96:651-656. CrossRef Medline

Jeewajee A, Lever C, Burton S, O'Keefe J, Burgess N (2008) Environmental novelty is signaled by reduction of the hippocampal $\theta$ frequency. Hippocampus 18:340-348. CrossRef Medline

Keselman HJ, Rogan JC (1980) Repeated measures F tests and psychophysiological research: controlling the number of false positives. Psychophysiology 17:499-503. CrossRef Medline

Kisley MA, Cornwell ZM (2006) $\gamma$ and $\beta$ neural activity evoked during a sensory gating paradigm: effects of auditory, somatosensory and crossmodal stimulation. Clin Neurophysiol 117:2549-2563. CrossRef Medline

Klimesch W, Doppelmayr M, Russegger H, Pachinger T (1996) $\theta$ band power in the human scalp EEG and the encoding of new information. Neuroreport 7:1235-1240. CrossRef Medline

Lisman JE, Grace AA (2005) The hippocampal-VTA loop: controlling the entry of information into long-term memory. Neuron 46:703-713. CrossRef Medline

Lisman J, Grace AA, Duzel E (2011) A neoHebbian framework for episodic memory: role of dopamine-dependent late LTP. Trends Neurosci 34: 536-547. CrossRef Medline

Litvak V, Eusebio A, Jha A, Oostenveld R, Barnes G, Foltynie T, Limousin P, Zrinzo L, Hariz MI, Friston K, Brown P (2012) Movement-related changes in local and long-range synchronization in Parkinson's disease revealed by simultaneous magnetoencephalography and intracranial recordings. J Neurosci 32:10541-10553. CrossRef Medline

Mölle M, Marshall L, Fehm HL, Born J (2002) EEG $\theta$ synchronization conjoined with $\alpha$ desynchronization indicate intentional encoding. Eur J Neurosci 15:923-928. CrossRef Medline

Münte TF, Heldmann M, Hinrichs H, Marco-Pallares J, Krämer UM, Sturm V, Heinze HJ (2007) Nucleus accumbens is involved in human action monitoring: evidence from invasive electrophysiological recordings. Front Hum Neurosci 1:11. CrossRef Medline 
Münte TF, Heldmann M, Hinrichs H, Marco-Pallares J, Krämer UM, Sturm V, Heinze HJ (2008) Contribution of subcortical structures to cognition assessed with invasive electrophysiology in humans. Front Neurosci 2:72-78. CrossRef Medline

Niedermeyer E, da Silva FL (2004) Electroencephalography: basic principles, clinical applications, and related fields. New York: Lippincott Williams and Wilkins.

Nyhus E, Curran T (2010) Functional role of $\gamma$ and $\theta$ oscillations in episodic memory. Neurosci Biobehav Rev 34:1023-1035. CrossRef Medline

O’Doherty JP (2004) Reward representations and reward-related learning in the human brain: insights from neuroimaging. Curr Opin Neurobiol 14:769-776. CrossRef Medline

Osipova D, Takashima A, Oostenveld R, Fernández G, Maris E, Jensen O (2006) $\theta$ and $\gamma$ oscillations predict encoding and retrieval of declarative memory. J Neurosci 26:7523-7531. CrossRef Medline

Paller KA, Kutas M, Mayes AR (1987) Neural correlates of encoding in an incidental learning paradigm. Electroencephalogr Clin Neurophysiol 67: 360-371. CrossRef Medline

Percival DB, Walden AT (1993) Spectral analysis for physical applications. Cambridge: Cambridge UP.

Samadani U, Baltuch GH (2007) First indirect localization according to the Morel atlas. In: Stereotactic atlas of the human thalamus and basal ganglia. Boca Raton, FL: CRC Press

Sauleau P, Eusebio A, Thevathasan W, Yarrow K, Pogosyan A, Zrinzo L, Ashkan K, Aziz T, Vandenberghe W, Nuttin B, Brown P (2009) Involvement of the subthalamic nucleus in engagement with behaviourally relevant stimuli. Eur J Neurosci 29:931-942. CrossRef Medline

Sederberg PB, Schulze-Bonhage A, Madsen JR, Bromfield EB, McCarthy DC, Brandt A, Tully MS, Kahana MJ (2007) Hippocampal and neocortical $\gamma$ oscillations predict memory formation in humans. Cereb Cortex 17: 1190-1196. CrossRef Medline

Stanislaw H, Todorov N (1999) Calculation of signal detection theory mea- sures. Behav Res Methods Instrum Comput 31:137-149. CrossRef Medline

Staudigl T, Zaehle T, Voges J, Hanslmayr S, Esslinger C, Hinrichs H, Schmitt FC, Heinze HJ, Richardson-Klavehn A (2012) Memory signals from the thalamus: early thalamocortical phase synchronization entrains $\gamma$ oscillations during long-term memory retrieval. Neuropsychologia 50:3519-3527. CrossRef Medline

Tsivilis D, Otten LJ, Rugg MD (2001) Context effects on the neural correlates of recognition memory: an electrophysiological study. Neuron 31: 497-505. CrossRef Medline

Voges J, Volkmann J, Allert N, Lehrke R, Koulousakis A, Freund HJ, Sturm V (2002) Bilateral high-frequency stimulation in the subthalamic nucleus for the treatment of Parkinson disease: correlation of therapeutic effect with anatomical electrode position. J Neurosurg 96:269-279. CrossRef Medline

Warner-Schmidt JL, Schmidt EF, Marshall JJ, Rubin AJ, Arango-Lievano M, Kaplitt MG, Ibañez-Tallon I, Heintz N, Greengard P (2012) Cholinergic interneurons in the nucleus accumbens regulate depression-like behavior. Proc Natl Acad Sci U S A 109:11360-11365. CrossRef Medline

Weidlich S, Lamberti G, Hartje W (2001) Diagnosticum für Cerebralschädigung, Ed 4. Bern: Huber.

Wittmann BC, Schott BH, Guderian S, Frey JU, Heinze HJ, Düzel E (2005) Reward-related fMRI activation of dopaminergic midbrain is associated with enhanced hippocampus-dependent long-term memory formation. Neuron 45:459-467. CrossRef Medline

Wood DA, Rebec GV (2004) Dissociation of core and shell single-unit activity in the nucleus accumbens in free-choice novelty. Behav Brain Res 152:59-66. CrossRef Medline

Zink CF, Pagnoni G, Martin ME, Dhamala M, Berns GS (2003) Human striatal response to salient nonrewarding stimuli. J Neurosci 23:8092-8097. Medline

Zink CF, Pagnoni G, Chappelow J, Martin-Skurski M, Berns GS (2006) Human striatal activation reflects degree of stimulus saliency. Neuroimage 29:977-983. CrossRef Medline 